\title{
Nasoendoscopy Decontamination and Traceability in the Emergency Unit Treatment Room Delivery of a Teaching Intervention
}

H. Ubhi, R. Costello, G. Roblin and D. Owens, ENT Department at University Hospital Wales, Cardiff, South Wales

\section{INTRODUCTION}

- Nasoendoscopy is a clinically invasive procedure

- Optimal decontamination is essential to minimise the risks of iatrogenic spread of infection or chemical injury to patients with proper documentation

- Our audit evaluates departmental compliance with ENT UK 2010 decontamination guidance using the Tristel regime $(1)$.

\section{STANDARDS}

- All nasoendoscopy cleaning episodes must be in accordance to the Tristel Four Stage Wipe System

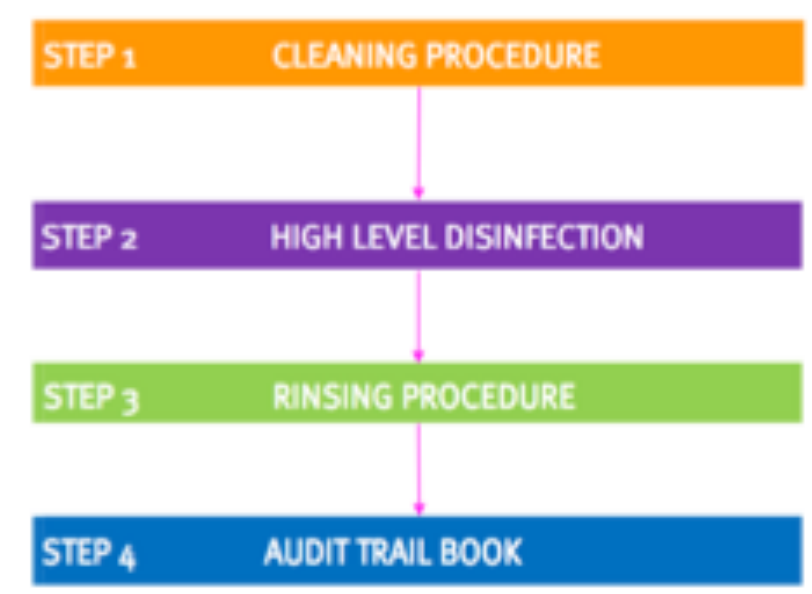

\section{METHODS}

- First Cycle: Aug - Sept. 2016: All nasoendoscopy cleaning entries in the Tristel Quality Audit Trail Record Book performed by ENT Junior Doctors

- Intervention: Sept. 2016: A Tristel decontamination tutorial was given to the ENT department, including all junior doctors

- Second Cycle: Oct - Nov. 2016: Consecutive cleaning episodes were re-audited after the intervention

\section{RESULTS}

First Cycle

- Total $=9$ Cleaning episodes

- Identified one trainee performing the majority of cleaning episodes (88.9\%)

- Standard compliance was high overall

- Lowest compliance at doctor signature and date (78\%)

\section{First Audit Cycle: Compliance}

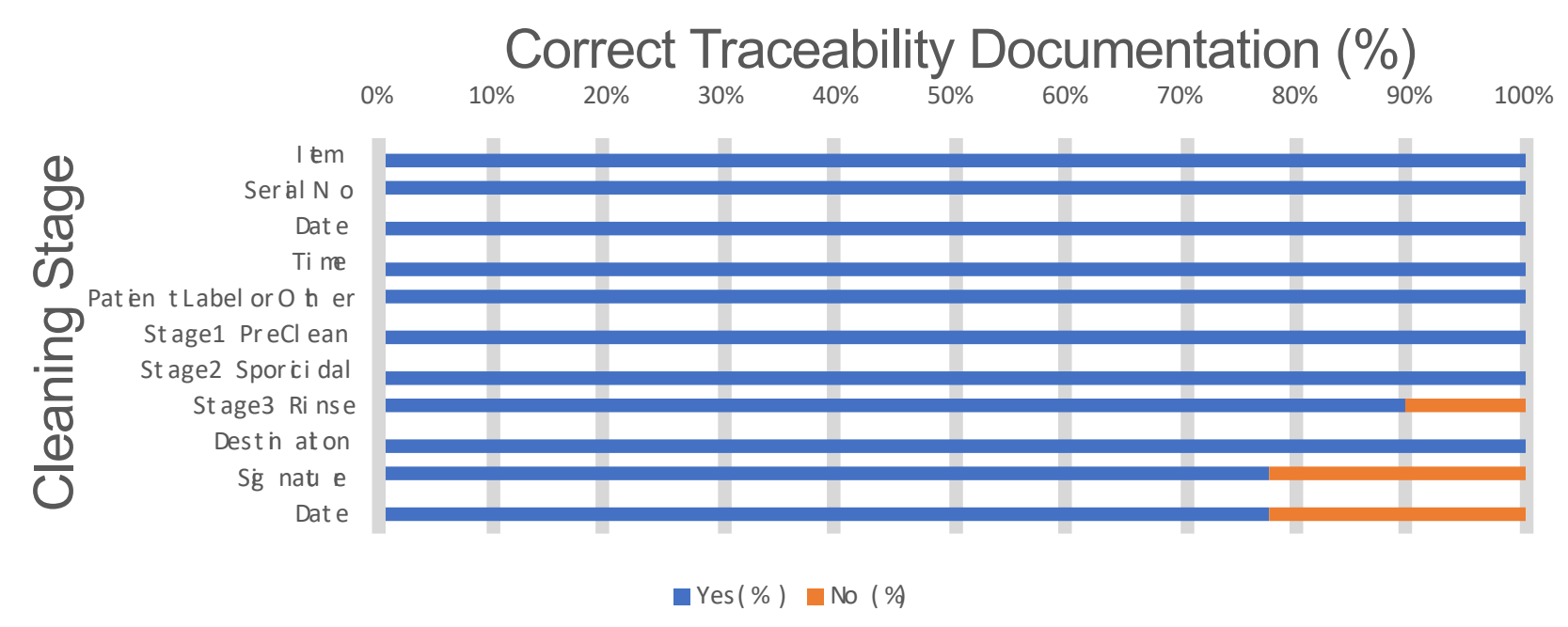

RESULTS (cont.)

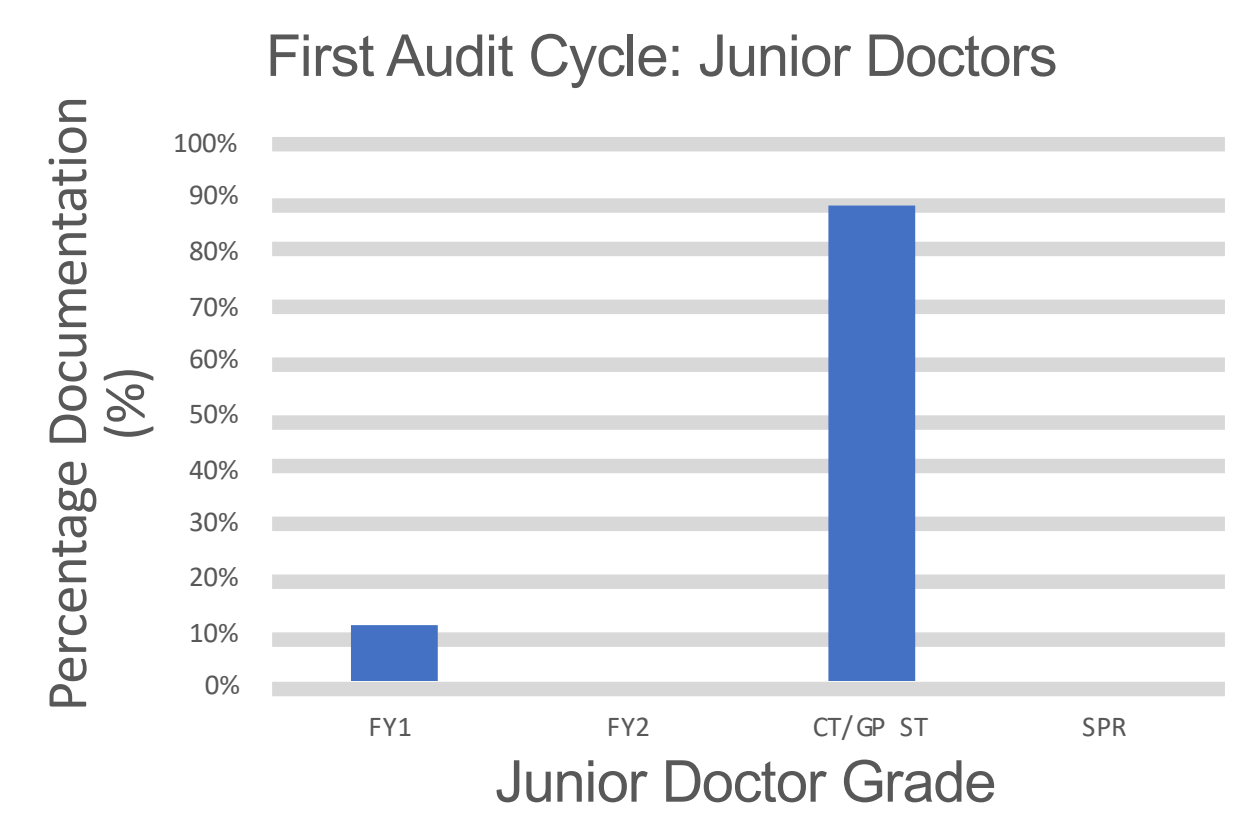

Second Cycle

- Total $=14$ Cleaning Episodes

- More trainees identified as documenting decontamination $(n=6)(p<0.001)$

- Standard compliance remained high with the exception of
doctor grade $(43 \%)$ and full patient details $(93 \%)$

Second Audit Cycle: Compliance

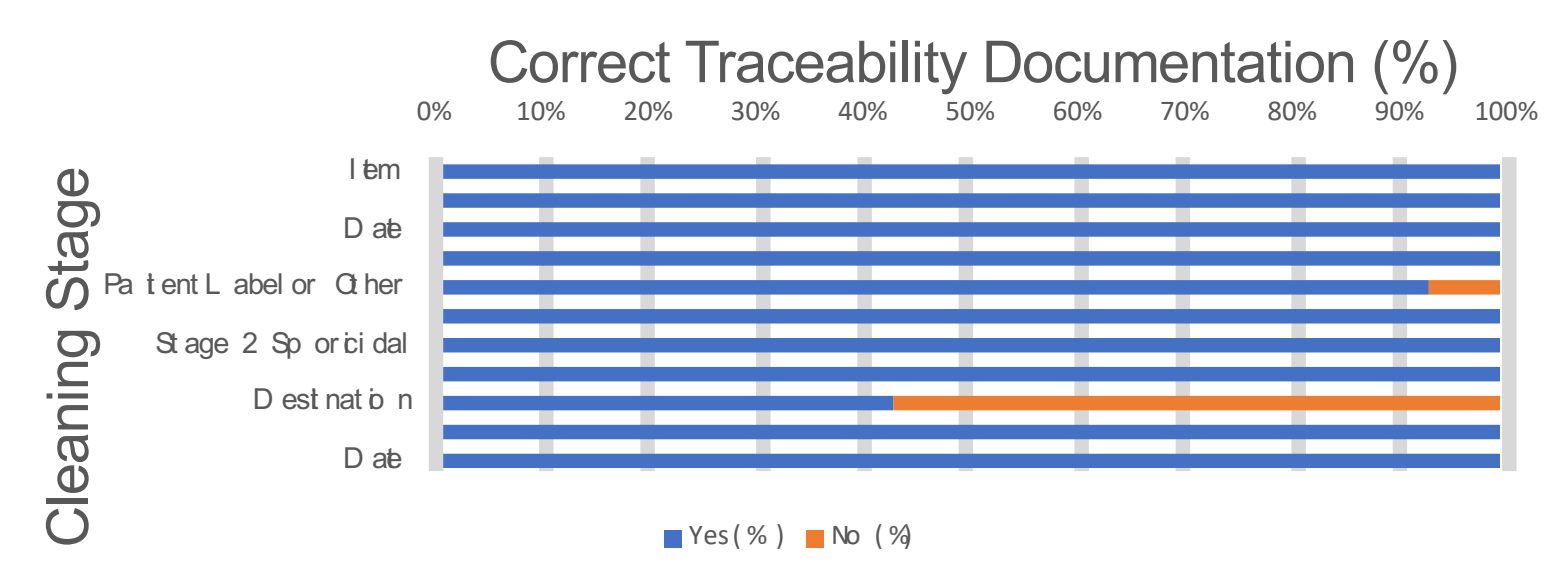

Second Audit Cycle: Junior Doctors

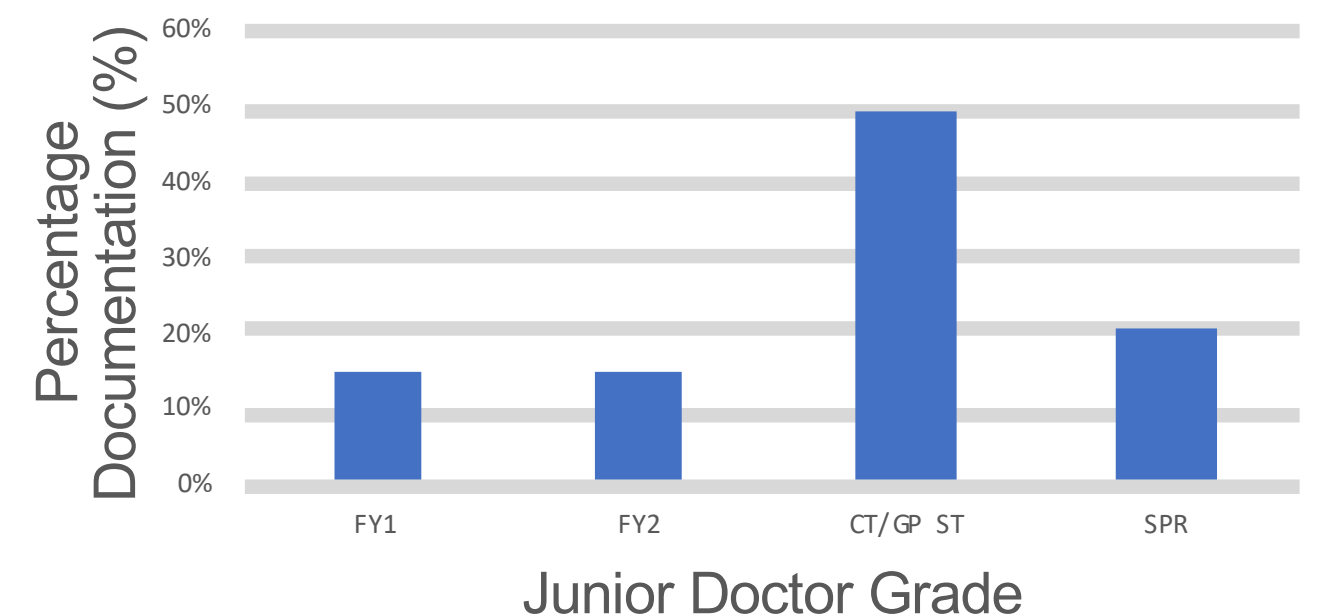

CONCLUSION

- Generally good compliance with the ENT UK guidelines

Our teaching session was effective in educating more trainees in the decontamination process with a similar number of compliance episodes

- Integration of nasoendoscope departmental tutorial at every subsequent ENT induction essential in continued adherence

\section{REFERENCE}

1. Guidance on the decontamination and sterilization of rigid and flexible endoscopes by Andrew Swift. Website: http://www tristel.it/wp/wp-
content/uploads/2014/12/ENT_UK_guidanceendoscopedecontamination.pdf 